\title{
New Discussion on the Planning and Design of the Chinese Revolutionary Memorial Square_— Taking Shandong Yinan Democracy Regime Memorial Square as an Example
}

\author{
Jing Zhao \\ Nanjing Institute of Railway Technology, Nanjing, Jiangsu, 210031
}

Keywords: Revolutionary Memorial Square, Planning and Designing, Urban Public Space

\begin{abstract}
With the development of the times and the concept of change, people on the revolutionary memorial square design and planning concept has also changed. This paper puts forward the design formula of the current Chinese Revolution Memorial Square, and through the design and planning of the Yinan Democracy Square in Shandong, a typical case of the Chinese Revolutionary Memorial Square, summed up the new method of contemporary revolutionary memorial square design New features.
\end{abstract}

\section{Introduction}

With the deepening of the pace of reform and opening up, Chinese urban construction with each passing day, people's lifestyles and life philosophy has also undergone tremendous changes. City Square as the city's public activity space began to pay more and more attention, it is not only people pastime, rest, but also access to information, into the social places, become an integral part of urban life.

\section{The Design of the Revolutionary Memorial Square}

Revolutionary Memorial Square, is a special type of city square, generally with a certain political color, the atmosphere more serious. Therefore, in the past for a long time, Chinese revolutionary memorial square planning and design into a misunderstanding, that is, highlight the revolutionary spirit of the rendering and dissemination, and even to emphasize this point and weaken the other functions of the square, the lack of human facilities and the art of infectious design, the revolutionary memorial square is reduced to a simple commemorative place.

However, the contemporary city square is a general definition of "to meet the needs of a variety of urban social life to build to the construction, roads, landscapes, terrain, etc., by a variety of soft and hard landscape composition, the use of walking means of transport, the theme of the idea and size of the node-type city outdoor public space "[1]. Which reflects the modern city square of some of the characteristics, such as to meet the needs of urban social public activities, with a certain considerable tourability and the surrounding environment and the overall coordination. Therefore, the modern city square should have three major functions: shaping the city image, to meet people's multi-level activities, the transformation of urban environment (including urban space environment and urban ecological environment) [2]. In the process of planning and design should follow the "humanistic" human design principles, pay attention to form and function at the same time, people-oriented, full consideration of human needs and activities. Square space tends to miniaturization, the scale is pleasant, the function should be leisure recreation mainly; second to cherish the cultural traditions, protect the historical sites. Modern urban square of the historical and cultural inheritance not only makes the urban space is individual and identifiable, but also makes the urban space with space-time continuity, and the public on the square with a sense of belonging and identity; In addition, should also consider the environmental quality. The public's desire for 
nature, so that the design of modern city square should be a scale and pleasant, vibrant "natural" square change, which is the modern city square and the traditional city square one of the important differences. Plants and water and other soft materials should be a large number of the introduction of the city square, to enhance the ecological benefits of the square.

As a sub-type in the city square, the planning and design of the modern revolutionary memorial square should also have and follow these functions and principles. In addition to cherishing the revolutionary deeds and revolutionary figures, carry forward the spirit of revolution, but also play a role in improving the urban ecological environment for the public to provide a good outdoor recreational recreation, to create a good urban landscape important role.

In the actual design process, how to combine the commemorative function with the leisure and recreational needs, how to combine the historical context with the spiritual and material demands of the modern society, and the planning and design of the commemorative square of the Yinan Democracy in Shandong Carried out to explore and practice.

\section{The Project Background of Revolutionary Memorial Square}

In 1990, in order to commemorate the establishment of Chinese first democratic regime, Yinan County camel town built the Shandong anti-Japanese democratic regime to create a memorial. In 2009, in order to further explore the history of Yinan red revolution, carry forward the Yimeng revolution in the fine tradition, and the development of Shandong Yinan red tourism, the local government plans to build a park around the site, including Shandong Yinan Democratic Memorial Square, the original memorial and the camel temple ruins to restore the park three parts. Shandong Yinan Democratic Regime Memorial Square as an important part of the park landscape, including the entrance from the park to the memorial hall before the large area of flood discharge, a major function, is the key point, the key to convergence of old and new landscape. How to reflect the characteristics of the new city square, while taking into account the political function and the new needs of the old title, is the designer in the planning process must think about the problem.

To this end, the designer in the planning and design, from the square of the spatial pattern, environmental atmosphere, ecological remediation in many ways, trying to different nature, different periods of landscape harmoniously into the park, to show the original revolutionary style, promote the revolution The spirit of the same time, taking into account the various functions of the city square to meet the modern needs of the city square. The planning and design of the commemorative square of Yinan Democracy in Shandong not only reflects some new features of the contemporary Chinese revolutionary memorial square, but also reflects the problems that China faces in the construction and reconstruction of the city square. It provides the construction of the revolutionary commemorative square in other areas.

\section{The Method and Characteristics of Revolutionary Memorial Square Design}

In addition to highlighting the revolutionary theme and promoting the revolutionary spirit, the planning and design of the contemporary revolutionary memorial square should also take into account the characteristics of the place. Shandong Yinan Democratic Regime Memorial Square planning and design not only need to reflect the contemporary revolutionary memorial square of the new features, in function and space also plays a role in the introduction and convergence of old and new landscape.

The Protection and Continuation of Historical Context. Shandong Yinan democratic regime to commemorate the planning of the square, not only in the open space to build a square problem, but also take into account how the new historical environment in the reproduction of the revolutionary style, and deal with the park in the memorial the relationship between the time and space span is very large, and these are the problems that must be solved when many of the revolutionary memorial squares are being built.

Review of revolutionary history in the new period. The theme of the commemorative square of Yinan Democracy in Shandong is to commemorate the revolutionary deeds before the founding of 
new China and it is very different from the current age environment. How can the local revolutionary historical style be reproduced in the new era so that the visitors can experience the experience in a short time to the kind of special historical environment to achieve the purpose of publicity, education, planning the design of the square is the primary consideration. This requires that, first of all, the designer must have a thorough understanding of this revolutionary history, and through a relatively concrete form to show it in front of all visitors, so that different age groups and different regions of the visitors can be more intuitive and more profound understanding and Perceive this history. At the same time as far as possible to retain or restore the historical value of the original landscape to reproduce the special environment at that time, enhance the spirit of the venue. Square, the original Shandong map of the ground pavement, reflecting the history of Yinan democratic revolutionary relief wall, as well as the height and composition of the monument elements, these details are designed to reflect the designer trying to highlight the theme of the design wishes.

Similarly, there are Baoding City, Langya Mountain Five Warriors Memorial Square planning and design. Designers in respect of the site, according to the principle of local conditions, the Langya Mountain Warrior bronze statue placed on the high $8 \mathrm{~m}$ base, on the design of the center point, close to the square design theme; in the vertical axis center Point 2/3 position along the fan-shaped arc to do the ribbon-like micro-terrain treatment, respectively, $1.5 \mathrm{~m}, 1.2 \mathrm{~m}, 1.2 \mathrm{~m}$ three high ground, the formation of three interconnected "turtle-shaped" hills to reach the continuous Ups and downs of the effect, point out the background of the incident - Langya Hill, while forming the level of the facade landscape, and echoed with the sculpture square [3]. This reflects the designer highlights the theme reproduce the revolutionary scene of the intended design.

City Square is generally open, surrounded by the boundaries of the square that is an important factor in its surrounding buildings, combined with the planning nature of the square protect those old buildings, the use of appropriate treatment, the surrounding building environment into the square environment, It is very important [4]. Even within the square, it is important to coordinate the relationship between the attractions, so it is important to note that the relationship between the interior landscape and the landscape area and the surrounding environment is very important based on the target environment, the whole landscape of the various parts of the coexistence, communion, harmonization.

As the interior landscape of the park in Shandong Yinan Democracy Memorial Square is large in the time span, the landscape design in each region must be harmonized to avoid the sense of breakage in time and space. Combined with the park near the Han Dynasty site green camel temple, memorial hall is with the new Chinese architectural design techniques, the main building with the Han Dynasty architectural features. Park Square on the meritorious pavilion, loyalty pavilion in the architectural design are used in the Han Dynasty architectural elements, appear vigorous atmosphere, highlighting the cultural characteristics of the region, more importantly, the transition between the old and new landscape harmony and natural, making the whole area is both clear and seamless.

In addition, the author learned that in the process of reconstruction of the Guangzhou Revolution Square also encountered similar problems and the department was the first time of the domestic revolutionary war, the revolutionary mass procession and rally place, workers pickets often rehearsal in the square. In order to reproduce the past style of the square, the square near the East Gate area will be built green square, reflecting the old city of Dongchengmen historical characteristics; Wende Road will build a cultural relics in Guangzhou, Yuexiu District, the traditional characteristics of the neighborhood, the square in series to restore Revolutionary square of the historical style, is a reasonable coordination of the city square inside and outside the landscape of the good example.

The Diversity and Innovation of Design Methods. It reflects the spirit of revolution, taking into account multiple functions. Reflecting the revolutionary spirit is the primary feature of the revolutionary memorial square. Shandong Yinan Democratic Regime Revolution Square in the layout still maintained the traditional revolutionary memorial square axis symmetrical pattern, along 
the axis design of a large revolutionary history group carving and relief wall. In the subsidence area near the east, the entrance is designed in the form of military badges both sides embody the embossed wall of the history of the democratic revolution in Yinan. The monument is built on the central square of the square with a height of 40.8 meters. The entrance to the west side of the park is 194.0 meters away from the memorial. The entrance is 81 meters away from the monument, forming both the visual focus and the landscape mark of the whole area. It also symbolizes the beginning of the revolution Time August 1, 1940. Monument body consists of five blocks, a symbol of the provincial government predecessor - the five constituent institutions of democracy: workers, agriculture, green, women and text. Through these details of the landscape design, fully embodies the square to commemorate the theme and revolutionary spirit.

The general function of the square is mainly to meet the needs of urban public activities, to provide people with a space for outdoor activities, so the design of the city square needs people-oriented from the environment, space scales, landscape facilities and other aspects should reflect the human the design of. Therefore, in the west of the monument, the designer created a large-scale water area with a combination of movement and movement, and the water area surrounded the monument square. The water body was equipped with a large fountain. The water body became a grand dynamic background of the monument and became a memorial Landscape "prospects, with the landscape before and after the opening effect. The spectacular fountain not only contrasts the solemn atmosphere, but also brings vitality and vitality to the square, improving the accessibility of the square. In addition, the embossed wall to the anti-Japanese history of the landmark scene as the main body, deepening the people's understanding of this revolutionary history and understanding, meritorious pavilion and loyalty hall along the flower beds designed to build a step, which planted evergreen trees and shrubs for people to stay, and rest sit small. The landscape leading to the spillway bridge has a garden-like visual style, more natural and simple, can slightly ease the visitors in the monument before the heavy mood. The design of these landscapes and public facilities on the one hand to meet the needs of people leisure activities, on the other hand to achieve a psychological soothing and comfort.

It emphasizes practical functions, taking into account the artistic value. Shandong Yinan Democratic Regime Square on both sides of the use of curved landscape area around, making the square of the overall layout is more full, more centripetal force, and further highlights the core area. The core area by the sink square, monument square, water area composition, the spatial level is more rich and varied, so that visitors in the process of walking can produce a different sense of space and visual experience, reflecting the combination of functional and artistic. Sinking of the entrance of the pavement, designed into the territory of Shandong Province during the revolutionary era, marked Linyi and Yinan where the location, both show the status of the Yinan region in the revolutionary history, but also enhance the square floor pavement artistic characteristics so that itself not only become a monumental function of the carrier, but also formed a beautiful landscape. Square axis set vertical guide array, to strengthen the depth of the square. Monument Square built on the platform plane, first of all from the visual enhancement of the square and the monument of the space gap and visual shock. At the same time, the overall appearance of the monument "mountain" shape, both out of the "Shandong" meaning, but also has a strong artistic effect. Water area surrounded by the entire monument square, the water body is arranged in a large fountain, constitute a huge historical background of the monument, both softening space, and static and dynamic combination, and plants and sculptures against each other, enhanced artistic and comfort, and enhance the microclimate environment, so that the entire square area more pleasant. These details of the design, not only to meet the various functions of the contemporary city square, but also highly artistic appeal.

It enriches square connotation, coordination of spatial structure. The use of variable construction techniques, to create a rich connotation and coordination of the square space, mainly in three aspects - "to promote a variety of square space composition, the natural green and water into the square design, straighten out the traffic relationship to create a suitable fit and rest of the practical square "[5]. These landscape elements have been well reflected in the planning and design of the 
revolutionary square of Shandong Yinan Democracy Regime, such as the rise of the sinking space, the design of the flower bed and the large fountain, the construction of the appropriate gathering space.

Reasonable organization and coordination of various spatial relationships is the most difficult place in the design of the square. The square is located in the south-east of the park, both the main entrance channel of the park, leading people to the memorial hall, the series from the inside and outside the park landscape, while the park is the prelude part of the park set off the focus monuments and memorials - two different time construction of the landscape, plays the role of convergence old and new landscape. In addition, there is a flood channel between the Memorial Hall and the Yinan Democracy Memorial Square, which is not conducive to the overall park environment in the landscape pattern, adding the difficulty of the design of the square.

In order to solve these problems, the designer in the planning and design in the square leading to the bridge before the bridge design of the water area, with water in the water area divided into different functional partitions, large fountain set off a monument, but also different style, different times of the memorial set a "barrier scene" prospects, with the landscape before and after the effect. In the pattern is also with the spillway on the bridge, river and bank landscape against each other.

\section{Conclusion}

City Plaza is an important part of the urban public environment, with the people's living environment requirements are getting higher and higher, the design of the city square is constantly updated and updated. [6] Revolutionary Memorial Square is a special element in the city square, it not only has to have the city square has a variety of characteristics, but also have to be a special function - used to commemorate the activities to the corresponding symbol and other means of teaching, educate people, infected people, in order to strengthen the object of commemoration, resulting in greater social benefits. It is also so, the revolutionary memorial square planning and design more complex and more difficult. Although the planning and design of the commemorative square in Yinan, Shandong Province cannot fully reflect all the problems encountered in the construction of the revolutionary memorial square, but it shows the distinctive characteristics of the times and the times will give the current domestic revolutionary memorial square the construction of the transformation brought a lot of useful thinking and inspiration.

\section{References}

[1] Wang Ke, Xia Jian, Yang Xinhai. City square design [M]. Nanjing: Southeast University Press, 1999.

[2] Bao Wengang, Liu Bo, on the planning and construction of the city square [J] Urban Road and Bridge, 2007 11, 103

[3] Bai Xiaoxia, Li Zhibin. Baoding Langya Mountain five warriors garden square design [J], Chinese urban industry, 2009.7 (3), 46

[4] Huang Yafeng, from the Nanyang Jiefang Square planning and design on the city to commemorate the square construction [J]. Urban and rural construction, 1999 11, 34-35

[5] Sun Peifang, Fang Xuming, Zheng Ruifeng. "City living room" diffuse - modern city square design example [J], construction, 2008 21, 67.

[6] Lin Yulian, Hu Zhengfan. Environmental Psychology[M]. Beijing: China Construction Industry Press, 2000. 